\title{
COMPARTIVE STUDY BETWEEN EPIDURAL ANALGESIA AND BILATERAL TRANSVERSUS ABDOMINIS PLANE BLOCK FOR POSTOPERATIVE PAIN RELIEF IN PATIENTS UNDERGOING CESAREAN DELIVERIES
}

By

\section{Abd Allah Ibrahim Ahmed Hassan El-Malla, Gamal lotfy Abd El- Rahman Gad and Badr Ismail Fadl-Allah El-far}

Anesthesiology and Intensive Care Department, Faculty of Medicine, Al-Azhar University

Corresponding Author: Abdallah Ibrahim Ahmed Hassan El-malla

E-mail: adallahelmalla92@gmail.com

\begin{abstract}
Background: Caesarean section (CS) is one of the most common surgical procedures in the world. Postoperative pain affects both mother and the newborn, particularly the first $48 \mathrm{~h}$ after birth. The pain can be terrifying, disturbing the bonding between the mother and the child.

Objectives: The aim of this study was to compare the efficacy and safety of continuous bilateral transversus abdominis plane block versus epidural analgesia for post-operative pain relief after cesarean deliveries.

Patients and Methods: Sixty Patients of American Society of Anesthesiologists (ASA) physical status I or II, scheduled for cesarean deliveries, were enrolled in this randomized, prospective, double-blind, clinical trial study after approval of the medical ethical committee at Al-Azhar university hospitals, Department of Anesthesia and after patients giving written consents, in the period from January 2020 till August 2020, Our study patients were randomly divided into two equal groups (epidural group and tap group).
\end{abstract}

Results: Epidural block provided significantly prolonged postoperative analgesia and reduced postoperative analgesic requirements as compared to ultrasound guided TAP block in patients undergoing CS. Both analgesic techniques were safe.

Conclusion: Epidural analgesia was better than TAP block regarding postoperative analgesia, total analgesic consumption and first time to rescue analgesia TAP block can be alternative to epidural when neuraxial anesthesia was contraindicated.

Keywords: Epidural Analgesia, Bilateral Transversus Abdominis Plane Block, Postoperative Pain Relief, Cesarean Deliveries.

\section{INTRODUCTION}

The well-known side effects of the analgesic morphine, such as nausea, vomiting, itching and sedation, may interfere in a dose dependent manner with the interaction between mother and child, breastfeeding and post-partum experience.
But a number of alternative strategies have been described to decrease morphine consumption post-operatively (Tan et al., 2012). One of those is the transversus abdominis plane (TAP) block, a regional anesthetic technique that can be able to give sensory and motor block of anterior abdominal wall from T10 to L1 although 
lacking any visceral effect. This is used for lower abdominal surgeries, as cesarean section (McDonnell and Paech, 2012).

The Interest in transversus abdominis plane (TAP) block increased in the last years after introduction of ultrasound in anesthetic practice (Baaj et al., 2010).

There are many benefits obtained by the TAP block for mother and baby as Long and effective analgesia, earlier oral nutrition, earlier mobilization and short hospital stay (Aluri and Wrench, 2014). Epidural analgesia has been the gold standard and time-tested technique for postoperative analgesia in lower abdominal surgeries. But contraindications for the same would warrant need for other equally good analgesic techniques (Iyer et al., 2017).

Epidural analgesia and ultrasoundguided transversus abdominis plane (TAP) block are ideal choices for analgesia following cesarean deliveries (Iyer et al., 2017).

The aim of this study was to compare the efficacy and safety of continuous bilateral transversus abdominis plane block versus epidural analgesia for postoperative pain relief after cesarean deliveries.

\section{PATIENTS AND METHODS}

The primary outcomes were pain scores at rest and on movement at 2, $4,8,12$ and 24 hours postoperatively.

The secondary outcomes was time to first rescue analgesic, number of rescue analgesic use, and related side effects as nausea and vomiting.

Sixty adult Patients of American Society of Anesthesiologists (ASA) physical status I or II, scheduled for cesarean deliveries, were enrolled in this randomized, prospective, clinical trial study after approval of the medical ethical committee at Al-Azhar university hospitals, Department of Anesthesia. All patients gave written informed consents.

The study was performed in Al-Azhar University Hospitals (Al-Hussein and Sayed Galal hospital). In our study, 60 patients were randomly divided into two equal groups: Epidural Analgesia (A Group) and continuous bilateral transversus abdominis plane (B Group).

\section{Inclusion criteria:}

ASA I to II patients, Aged between 21 and 45 years.

\section{Exclusion criteria:}

1. Patient refusal.

2. Known allergy to local anesthetics.

3. Body mass index $>35 \mathrm{~kg} \mathrm{~m} \_2$.

4. History of chronic use of opioids.

5. Emergency cesarean section.

6. Coagulopathy.

7. Infection at puncture site.

Patients were assessed preoperatively by evaluation of their medical history, laboratory investigations, Patient's Preparation was done by IV Cannulation by $18 \mathrm{G}$ cannula, and infusion of $500 \mathrm{ml}$ Ringer Solution was started about 20 minutes before anesthesia induction.

Standard monitoring was applied which included electrocardiography (ECG), noninvasive blood pressure and pulse oximetry for peripheral oxygen saturation (SPO2) after reaching the operating room. After obtaining baseline 
vital signs, patients were divided in to two groups: Group A and Group B, Both groups were given general anesthesia.

\section{Technique of epidural insertion:}

Patient was placed in sitting position and after sterilization of her back by Betadine solution a lumbar epidural catheter was inserted in L3-L4 or L4-L5 region using a median approach or paramedian approach. An 18G Tuohy needle was inserted after local anesthesia of the puncture site. The Lumbar epidural space was identified by loss of resistance to air by intermittent compression of the syringe plunger attached to Touhy needle. After identifying the space, a multi orifice $20 \mathrm{G}$ epidural catheter was placed 3-4 cm within the epidural space. After removal of the needle, a sterile sponge or gauze was applied at the epidural insertion site and an occlusive clear dressing was placed over the catheter and sponge. After placement of the catheter and after negative aspiration for CSF or blood, test dose of $3 \mathrm{ml}$ Lidocaine was injected to exclude intrathecal position or intravascular position.

\section{Technique of TAP block:}

General anesthesia was given to the patient, at the end of surgery, linear US probe (high frequency probe $10-12 \mathrm{MHz}$ ) connected to a portable US unit (SonoSite, USA) was placed in the mid-axillary plane midway between the lower costal margin and the highest point of iliac crest with the patient in supine position. After skin disinfection, a 23-G 50-mm needle with an injection line was inserted in plane with the probe. Once the tip of the needle was placed in the space between the internal oblique abdominal muscle and transversus abdominis muscle, and after negative aspiration, $5 \mathrm{ml}$ saline $0.9 \%$ was injected to distend the transversus abdominis plane, then $20 \mathrm{ml}$ of local 10 $\mathrm{ml}$ Bupivacaine $0.5 \%$ and $10 \mathrm{ml}$ Lidocaine $2 \%$ was injected.

\section{The following parameters were assessed and recorded:}

1. Hemodynamic monitoring: mean arterial blood pressure and heart rate were recorded every 15 minutes in the first postoperative hour then at 2, 4, 6, 12 hours postoperatively.

2. Respiratory monitoring: peripheral oxygen saturation (SPO2) was recorded every 15 minutes in the first hour postoperative then at 2, 4, 6, 12 hours postoperatively.

3. Assessment for post-operative pain using Visual Analogue Scale Score: Every 15 minutes for the first postoperative hour then at 2, 4, 6, 12 hours postoperatively.

4. Analgesic requirements (Rescue analgesic): The first time to rescue analgesic Nalbuphine $(0.1 \mathrm{mg} / \mathrm{kg})$ was recorded in both groups it was determined when VAS reached 4 and The total consumption of analgesia in first 12 hours postoperatively was recorded in both groups.

5. Post operative Nausea and Vomiting: the incidence of postoperative nausea and vomiting was assessed in both groups in first 12 hours and average consumption of rescue antiemetic doses of Granisetron (1mg) was recorded in both groups.

6. The time to hospital discharge was recorded. 
Statistical analysis:

Data management and statistical analysis were performed using the Statistical Package for Social Sciences (SPSS) version 20. Numerical data were summarized using means and standard deviations or medians and ranges. Data were explored for normally using Kolmogrov-Smirnov test and ShapiroWilk test. Categorical data were summarized as percentages. Comparisons between the 2 groups with respect to normally distributed numeric variables were done using the Independent t-test. Non normally distributed numeric variables were compared by MannWhitney test. For categorical variables, differences were analyzed with (X2) (chi square) test and Fisher's exact test when appropriate. P-values $<0.05$ were considered significant.

\section{RESULTS}

Regarding demographic data, ASA and duration of surgery, there was no statistically significant difference between group A and group B (Table 1).

Table (1): Comparison between group A (Epidural) and group B (TAP block) according to demographic data, ASA and duration of surgery

\begin{tabular}{|c|c|c|c|}
\hline $\begin{array}{ll} & \text { Groups } \\
\end{array}$ & $\begin{array}{c}\text { Group A Epidural } \\
(\mathbf{n}=\mathbf{3 0})\end{array}$ & $\begin{array}{c}\text { Group B TAP block } \\
(\mathbf{n}=\mathbf{3 0})\end{array}$ & p-value \\
\hline Age (years) & \multirow[b]{2}{*}{$29.97 \pm 6.45$} & \multirow[b]{2}{*}{$29.10+6.58$} & \multirow[b]{2}{*}{0.608} \\
\hline Mean \pm SD & & & \\
\hline \multicolumn{3}{|l|}{ Sex } & \multirow{3}{*}{0.432} \\
\hline Female & $14(46.7 \%)$ & $11(36.7 \%)$ & \\
\hline Male & $16(53.3 \%)$ & $19(63.3 \%)$ & \\
\hline BW (kg) & \multirow[b]{2}{*}{$59.70 \pm 6.83$} & \multirow[b]{2}{*}{$60.33 \pm 5.97$} & \multirow[b]{2}{*}{0.704} \\
\hline Mean \pm SD & & & \\
\hline \multicolumn{3}{|l|}{ ASA } & \multirow{3}{*}{0.718} \\
\hline I & $26(86.7 \%)$ & $25(83.3 \%)$ & \\
\hline II & $4(13.3 \%)$ & $5(16.7 \%)$ & \\
\hline Duration of surgery (min) & \multirow[b]{2}{*}{$46.37 \pm 9.25$} & \multirow[b]{2}{*}{$48.13 \pm 8.70$} & \multirow[b]{2}{*}{0.449} \\
\hline Mean \pm SD & & & \\
\hline
\end{tabular}

Baseline MAP was comparable between the two study groups with no statistically significant difference. After 15,30 and 45 minutes in PACU, the MAP was significantly lower in group A when compared with group B. In the subsequent recordings, there was no statistically significant difference between group A and group B (Table 2). 
Table (2): Comparison between group A (Epidural) and group B (TAP block)according to Mean arterial blood pressure ( $\mathrm{mmHg})$

\begin{tabular}{|c|c|c|c|}
\hline $\begin{array}{ll}\text { Time of assessment } & \text { Groups } \\
\end{array}$ & $\begin{array}{c}\text { Group A: Epidural } \\
(\mathrm{n}=\mathbf{3 0})\end{array}$ & $\begin{array}{c}\text { Group B: TAP block } \\
(\mathbf{n}=30)\end{array}$ & p-value \\
\hline Baseline (At PACU) & $79.91 \pm 1+2.25$ & $77.90 \pm 11.76$ & 0.505 \\
\hline After15 min. & $68.88 \pm 9.51$ & $74.81 \pm 10.98$ & 0.0291 \\
\hline After $30 \mathrm{mi}$ & $65.87 \pm 8.52$ & $72.37 \pm 9.52$ & 0.008 \\
\hline After45 min & $62.94 \pm 7.52$ & $69.53 \pm 8.44$ & 0.002 \\
\hline After $60 \mathrm{~min}$ & $62.87 \pm 9.33$ & $65.87 \pm 7.93$ & 0.184 \\
\hline After 2hrs & $63.86 \pm 7.67$ & $66.55 \pm 8.52$ & 0.203 \\
\hline After 4 hrs & $64.88 \pm 8.77$ & $67.65 \pm 9.14$ & 0.236 \\
\hline After 6hrs & $68.32 \pm 7.92$ & $70.87 \pm 10.43$ & 0.291 \\
\hline After 12 hrs & $67.98 \pm 11.75$ & $69.88 \pm 9.43$ & 0.492 \\
\hline
\end{tabular}

Baseline VAS was comparable between the two study groups with no statistically significant difference between intergroup. In the subsequent measurements, the VAS was significantly lower in group A compared to that of group B (Table 3).

Table (3): Comparison between group A(Epidural) and group B (TAP block) according to visual analogue score

\begin{tabular}{|l|c|c|c|}
\hline $\begin{array}{c}\text { Groups } \\
\text { Time of assessment }\end{array}$ & $\begin{array}{c}\text { Group A: Epidural } \\
(\mathbf{n = 3 0})\end{array}$ & $\begin{array}{c}\text { Group B: TAP block } \\
(\mathbf{n = 3 0})\end{array}$ & p-value \\
\hline 0 min. (At PACU) & $3.24 \pm 1.62$ & $3.52 \pm 1.31$ & 0.464 \\
\hline After 15 min. & $2.15 \pm 1.13$ & $2.91 \pm 1.26$ & 0.01 \\
\hline After 30 min. & $2.02 \pm 1.24$ & $2.88 \pm 1.15$ & 0.007 \\
\hline After 45 min. & $1.86 \pm 1.12$ & $2.65 \pm 1.02$ & 0.006 \\
\hline After 60 min. & $1.77 \pm 1.01$ & $2.47 \pm 1.16$ & 0.015 \\
\hline After2 hrs. & $1.85 \pm 0.68$ & $2.33 \pm 0.97$ & 0.030 \\
\hline After4 hrs. & $1.74 \pm 0.73$ & $2.15 \pm 0.66$ & 0.026 \\
\hline After 6 hrs & $1.64 \pm 0.52$ & $1.95 \pm 0.56$ & 0.030 \\
\hline After 12 hrs & $1.53 \pm 0.46$ & $1.88 \pm 0.77$ & 0.032 \\
\hline
\end{tabular}

The first time to rescue analgesic was significantly longer in group A (epidural) compared to that of group B with significantly higher total rescue analgesia consumption in the 1 st 12 hours postoperatively in group B (TAP block) compared with group A. ( Table4 \& 5 )

Table (4): Comparison between group A: Epidural and group B: TAP block according to time of first dose of rescue analgesia

\begin{tabular}{|c|c|c|c|}
\hline & $\begin{array}{c}\text { Group A: } \\
\text { Epidural }(\mathbf{n = 3 0})\end{array}$ & $\begin{array}{c}\text { Group B: TAP } \\
\text { block }(\mathbf{n = 3 0})\end{array}$ & p-value \\
\hline $\begin{array}{c}\text { Time of first dose of rescue analgesia } \\
(\mathrm{min})\end{array}$ & $312.50 \pm 20.63$ & $264.00 \pm 15.35^{*}$ & $<0.001$ \\
\hline
\end{tabular}



Table (5): Comparison between group A: Epidural and group B: TAP block according to total dose of Nalbuphine consumption $(\mathrm{mg})$ in first 12 hours postoperatively

\begin{tabular}{|c|c|c|c|}
\hline & $\begin{array}{c}\text { Group A: } \\
\text { Epidural }(\mathbf{n}=\mathbf{3 0})\end{array}$ & $\begin{array}{c}\text { Group B: } \\
\text { TAP block }(\mathbf{n}=\mathbf{3 0})\end{array}$ & p-value \\
\hline $\begin{array}{c}\text { Total dose of Nalbuphine } \\
\text { consumption }(\mathrm{mg})\end{array}$ & $11.4 \pm 3.2$ & $18.7 \pm 3.8$ & $<0.001$ \\
\hline
\end{tabular}

\section{DISCUSSION}

As regard the demographic data (in terms of age, height, weight, BMI) and surgical durations there were no statistically significant difference between both groups.

In the current study, the baseline mean arterial blood pressure was comparable between the two study groups with no statistically significant difference. After 15,30 and 45 minutes in PACU, the MAP was significantly lower in group A when compared with group B. In the next recordings, there was no statistically significant difference between both groups. Baseline MAP was comparable in both groups with no statistical difference between them, but the MAP was significantly lower in lumbar epidural group when compared with TAP block group at $1^{\text {st }} 30$ minutes postoperative with no intergroup significant difference.

The same results were observed by Ismail et al. (2018) compared lumbar epidural analgesia versus transversus abdominis plane block for postoperative analgesia after lower abdominal surgery in 60 adult patients, and they attributed the drop of the blood pressure in the epidural group to the sympatholytic properties of the epidural block to the lower half of the body compared with TAP block which does not interfere with the sympathetic innervation of the lower half of the body while both lumber epidural and TAP groups showed no significant difference in their heart rates records and they attributed that to the analgesic effect of both lumbar epidural and TAP blocks. Our results were consistent with another study by Ebru et al. (2018) who compared the analgesic efficacy of transversus abdominis plane block versus lumbar epidural block in 80 adult patients after elective cesarean delivery. The MAP was significantly lower in lumbar epidural group when compared with TAP block group at $10,20,40$ minutes postoperatively.

As regard the respiratory parameters recorded; in the current study, there was no statistically significant difference between group A (Epidural) and group B (TAP block) according to $\mathrm{SpO} 2 \%$ recordings. No patient had desaturation episodes in both groups which could be attributed to multiple factors including first the nature of the surgeries of the current studies being lower abdominal with transverse incision with less impact on diaphragmatic function, second the analgesic effect of both modalities used in the current study which diminished the effect of post-operative pain on respiratory function, lastly the exclusion of obese patients in the current study.

As regard the analgesic parameters recorded in the current study, the VAS was significantly lower in group A 
(Epidural) when compared with that of group B (TAP block), and showed marked significant difference between both groups at 15, 30, 45 and 60 minutes postoperative and significant difference between both groups at $2^{\text {nd }}, 4^{\text {th }}, 6^{\text {th }}$ and $12^{\text {th }}$ hours postoperatively with significantly longer time to $1^{\text {st }}$ rescue analgesic in group $\mathrm{E}$ (epidural) compared to that of group $\mathrm{T}$ (TAP block) and statistically significantly higher total rescue analgesic consumption in the $1^{\text {st }} 12$ hours postoperatively in group $\mathrm{T}$ (TAP block) compared with group $\mathrm{E}$ (epidural) denoting greater pain control in epidural analgesia group when compared with TAP group.

In contrast to the findings of the current study, Abdelaal et al. (2015) found that, this might be attributed to the fact that the TAP is relatively poorly vascularized, so the drug clearance may be slowed.

The findings of the current study agree with those of Yiquan et al. (2013) who have performed their study on patients undergoing elective radical gastrectomy and have received either combined general-subcostal TAP anesthesia, combined general-epidural anesthesia, or general anesthesia. Group epidural was superior to group TAP regarding VAS pain scores at all points of comparison (PACU, 1, 3, 6,24,48,72 hours) and less morphine consumption over the 24 hours. EA group showed more drop in MAP and no heart rate variability between two groups.

Another study by $W u$ et al. (2013) showed comparable results to our study. They compared the analgesic efficacy of single injection transversus abdominis plane block to epidural analgesia and intravenous opioid analgesia after gastrectomy). Continuous epidural analgesia has been shown to provide more effective analgesia than single injection TAP block, which had increased morphine consumption and pain scores in the PACU and in the $1^{\text {st }} 24$ hours, That was attributed to reasons TAP block provides somatic pain relief only as opposed to epidural anesthesia which provides both somatic and visceral analgesia, also the effectiveness of single injection subcostal TAP block will wane over time, while that of epidural catheters can be sustained.

Contradictory results to our data, Ismail et al. (2018) who found that no significant difference as regard the VAS recorded at 2,4,6,12 hours postoperative, the total postoperative analgesic intake and the first time to rescue analgesia post operatively between lumbar epidural group versus TAP block group, and this difference in the results from those obtained in the current study could be contributed to the different protocol used in their study in the maintenance of epidural analgesia as they maintained the epidural analgesia by intermittent boluses technique of epidural bupivacaine $0.125 \%$ (1/2 loading dose) which was given every 2 hours rather than epidural bupivacaine $0.125 \%$ by infusion which was used in the current study.

Another contradictory result to our data have been reported by Niraj et al. (2014) which compared the effectiveness of continuous transversus abdominis plane analgesia with epidural analgesia in 70 patients following laparoscopic colorectal surgery. They had found no significant difference in visual analogue scores for the first $24 \mathrm{~h}$ between the TAP group and 
the epidural group. Also, there were no significant differences between the two groups for tramadol consumption over 48 h. In addition, the TAP group had a higher level of satisfaction, and this difference in the results from those obtained in the current study could be contributed to the usage of continuous TAP block catheter analgesia rather than single injection used in the our study.

Contradictory results to our data have been reported by retrospective propensity matched cohort study performed by Ayad et al. (2016) they tested the primary hypothesis that TAP infiltration was not inferior to continuous epidural analgesia and superior to continuous intravenous opioid analgesia. This difference in the results could be attributed to the usage of liposomal bupivacaine in their single injection TAP block which differs in its pharmacokinetics from bupivacaine used in our study by its more sustained released nature and longer duration of action than bupivacaine.

As regards the incidence of postoperative nausea and vomiting in the current study; there was no statistically significant difference between both groups.

Postoperative nausea and vomiting (PONV) were common annoying complains to patients particular during the first 12 hours following surgery, for fearing of wound dehiscence. Since opioids given via intravenous method proved to have many disadvantages, including PONV and a delay in the recovery of body functions such as bowel movement and mobilization, several studies have focused on the use of regional analgesia to overcome this complain postoperatively (Shah et al., 2014).

As regards to time of hospital discharge, there was no significant statistical difference between both groups as regards the hospital stay which was supported by studies conducted by Gasanova et al. (2017) and Ismail et al. (2018) in a comparison between both groups as regards time to hospital discharge and there was no significant difference between both epidural and TAP block group.

\section{CONCLUSION}

Both modalities in Cesarean section are important for post-operative analgesia. Epidural analgesia was better than TAP block regarding postoperative analgesia, total analgesic consumption and first time to rescue analgesia, with comparable nausea and vomiting and time of hospital discharge.

\section{REFERENCES}

1. Abdelaal, W., Metry, A. A., Refaat, M., Ragaei, $M$ and Nakhla, G. (2015): Comparative study between levobupivacine versus levobupivacaine plus dexmedetomidine for transversus abdominis plane block "tap" in post-operative pain management after abdominoplasty. Enliven: J Anesthesiol Crit Care Med , 2(2):004-006.

2. Aluri, S and Wrench, I. J. (2014): Enhanced recovery from obstetric surgery: a UK survey of practice. International Journal of Obstetric Anesthesia, 23(2): 157-160.

3. Ayad S, Rovnat B,Hesham E, Vinayak N, Chetan L and Natalya M (2016): Comparison of Transversus Abdominis Plane Infiltration with Liposomal Bupivacaine versus Continuous Epidural Analgesia versus Intravenous Opioid Analgesia: PLoS ONE, 11(4): $\mathrm{e} 0153675$. 
4. Baaj JM, Alsatli RA, Majaj HA, Babay ZA and Thallaj AK (2010): Efficacy of ultrasound-guided transversus abdominis plane (TAP) block for post cesarean section delivery analgesia--a double-blind, placebo-controlled, randomized study. Middle East J Anesthesiol., 20: 821-826.

5. Ebru C, Ahmet G, Zubeyir C, Bulent $H$ and Anil K (2018): The Analgesic Efficacy of Trans- versus Abdominis Plane Block versus Epidural Block after Caesarean Delivery Pain Research and Management, Article ID 3562701, 7 pages postoperative recovery, Lancet, 362-366.

6. Gasanova, I., Alexander, J., Ogunnaike, B., Hamid, C., Rogers, D., Minhajuddin, A., and Joshi, G. P. (2015): Transversus abdominis plane block versus surgical site infiltration for pain management after open total abdominal hysterectomy. Anesthesia \& Analgesia, 121(5), 1383-1388.

7. Ismail AS, Ahmed MG and Walid NS (2018): Comparative Study between Lumbar Epidural versus Transversus Abdominis Plane Block for Postoperative Analgesia after Lower Abdominal Surgeries. The Egyptian Journal of Hospital Medicine 72(7): 4903-4912

8. Iyer SS, Bavishi H, Mohan CV and Kaur $\mathbf{N}$ (2017): Comparison of epidural analgesia with transversus abdominis plane analgesia for postoperative pain relief in patients undergoing lower abdominal surgery: a prospective randomized study, Anesthesia: Essays and Researches, 11(3): 670-675.
9. McDonnell NJ and Paech MJ (2012): The transversus abdominis plane block and postcesarean analgesia: are we any closer to defining its role?Int J Obstet Anesth., 21: 109_ 11.

10. Niraj G, Kelkar A, Jeyapalan I, Graff-Baker P, Williams $O$ and Darbar A (2014): Comparison of analgesic efficacy of subcostal transversus abdominis plane blocks with epidural analgesia following upper abdominal surgery. Anaesthesia, 66:465-71.

11.Shah, P. K., Kore, S. and Hegde, A. (2014): General Care Principles in Surgery. Operative Obstetrics \& Gynecology, 14. (3): 379-384.

12. Tan TT, Teoh WH, Woo DC, Ocampo CE, Shah MK and Sia AT (2012): A randomised trial of the analgesic efficacy of ultrasoundguided transversus abdominis plane block after caesarean delivery under general anaesthesia. Eur J Anaesthesiol., 29: 88-94.

13. Wu Y, Liu F and Tang $H$ (2013): The analgesic efficacy of sub- costal transversus abdominis plane block compared with thoracic epidural analgesia and intravenous opioid analgesia after radical gastrectomy. AnesthAnalg., 117(2):507-13.

14. Yiquan W, Fuli L, Hongli T, Quanguang W, Limei C and Hui W (2013): The Analgesic Efficacy of Subcostal Transversus Abdominis Plane Block Compared with Thoracic Epidural Analgesia and Intravenous Opioid Analgesia After Radical Gastrectomy. AnesthAnalg., 117: 507-13. 


\section{دراسة مقارتة بين تاثير تسكين ما فوق الأم الجافية واغلاق مستوي

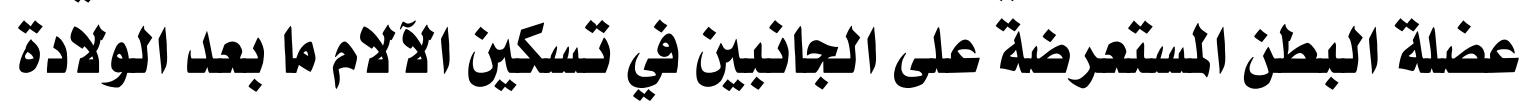 القيصرية الومايكية}

عبد الله ابراهيم احمد حسن، جمال لطفي عبد الرحمن، بدر اسماعيل فضل الله قسم التخدير و الرعاية المركزة، كلية الطب، جامعة الازهر

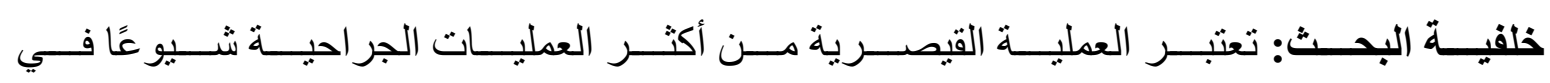

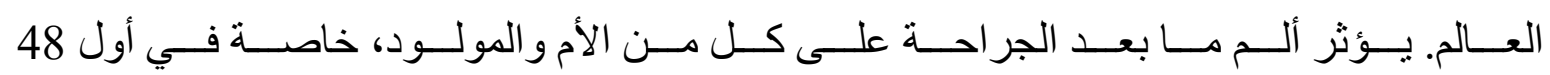
ساعة بعد الو لادة. يمكن أن يكون الألم مرعبًا، ويخل بالعلاقة بين الأم و الطفل.

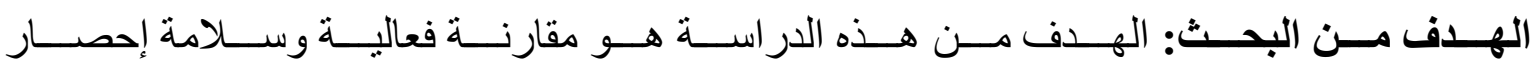

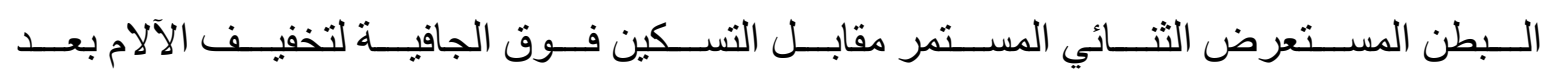
الو لادات القيصرية.

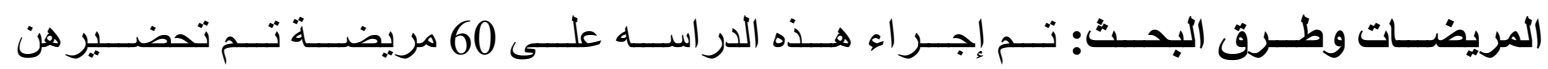

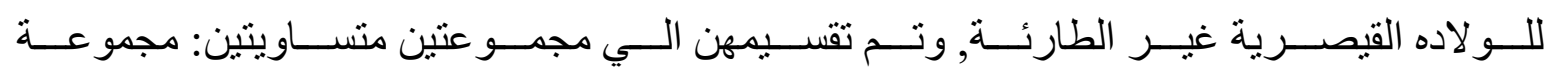

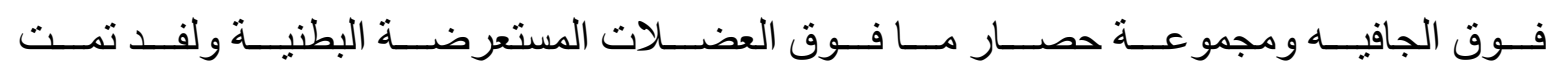

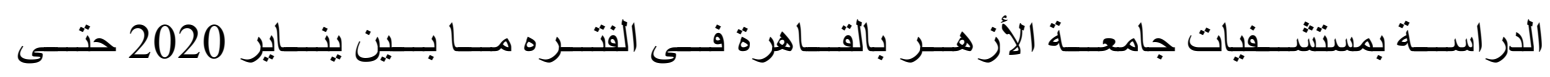

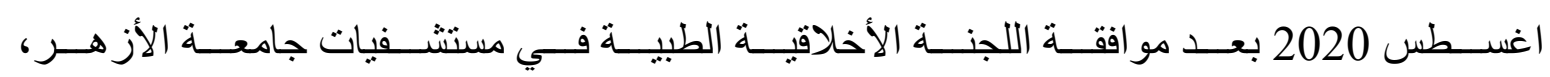
وبعد كتابة المريضات مو افقات كتابية.

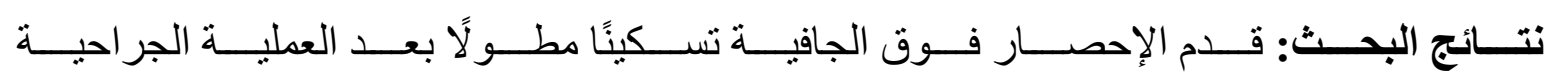

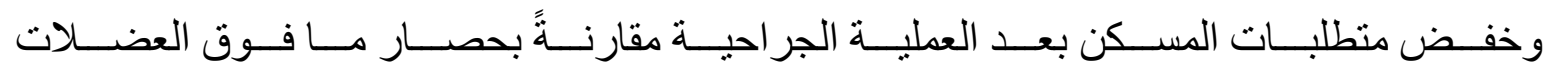

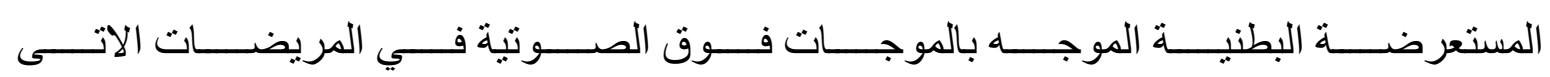
يخضعن للو لادات القيصرية وكانت كلتا تقنيات المسكنات آمنة.

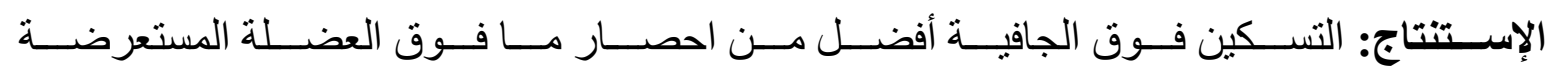

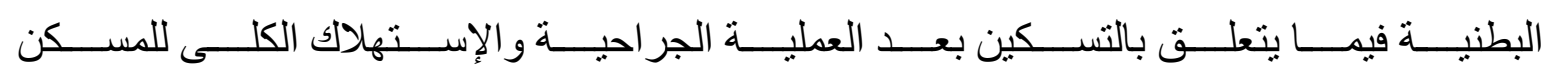

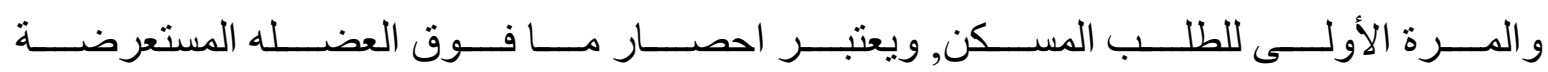
البطنية بديلا عن التسكين فوق الجافية عندما يكون استخدامه محظور ال. 